\title{
A phenomenographic study of students' conceptions of quality in learning in higher education in Rwanda
}

Penelope Mbabazi, Andreas Fejes and Lars-Owe Dahlgren

\section{Linköping University Post Print}

N.B.: When citing this work, cite the original article.

This is an electronic version of an article published in:

Penelope Mbabazi, Andreas Fejes and Lars-Owe Dahlgren, A phenomenographic study of students' conceptions of quality in learning in higher education in Rwanda, 2013, Studies in Continuing Education.

Studies in Continuing Education is available online at informaworld ${ }^{\mathrm{TM}}$ :

http://dx.doi.org/10.1080/0158037X.2013.768229

Copyright: Taylor \& Francis (Routledge)

http://www.routledge.com/

Postprint available at: Linköping University Electronic Press

http://urn.kb.se/resolve?urn=urn:nbn:se:liu:diva-87127 


\section{A phenomenographic study of students' conceptions of quality in learning in higher education in Rwanda}

Penelope Mbabazi Bamwesiga, Andreas Fejes, Lars Owe Dahlgren

Department of Behavioural Sciences and Learning, Linköping University, Sweden

Published in Studies in Continuing Education.

\section{Abstract}

The aim of this study is to understand the different ways that university students conceptualise quality in learning by drawing on a phenomenographic approach. A total of 20 students in higher education in Rwanda were interviewed, and analysis of the interviews generated an outcome space of conceptions of quality in learning as transformation, practice, knowledge durability, and employability. The findings illustrate the importance of the relationship between education and work as an important aspect of conceptions of quality in learning. This relationship connects to the discourse of employability in which graduates are expected to become flexible and adaptable to changes in context and over the course of time.

Key words: quality in learning, phenomenography, higher education

\section{Introduction}

As higher education systems around the world are pressed to improve their effectiveness in various ways, it becomes increasingly important to enhance the quality of learning and teaching (Knight \& Yorke, 2003). At a minimum, students should learn something; and one would prefer that there is also quality in the learning taking place. However, what constitutes quality is a debated issue. 
Governments position education as a remedy that can be used to make countries or regions more competitive in a globalised knowledge-based society. Thus, government policies often assume quality in learning to be that which is useful and can lead to the employability of students (cf. Fejes, 2010). According to Stråth (2000) and Williams (2005), emphasis is placed on the importance of a citizen being employable, noting that employability is currently used as an explanation (and to some extent a legitimisation) of unemployment.

Furthermore, quality in learning is a central issue for all people involved in higher education, and there are different conceptions of quality of education that inform the preferences of different higher education stakeholders. Harvey and Green (1993) group different ways of conceptualising quality into the following five discrete but interrelated categories: quality as exceptional, quality as perfection or consistency, quality as fitness for purpose, quality as value for money, and quality as transformation.

Another way of understanding quality in learning as presented in the literature is through the taxonomy structure. Biggs and Collis (1982) suggest a structure of learning outcomes (SOLO) in the form of levels of understanding, and these learning outcomes can be used to explain the quality of learning attained by students. The SOLO taxonomy associates quality learning with understanding, and interpretation is focused on the capacity of students to construct meaning from their learning tasks, to recognise the significance of parts by integrating them into a coherent whole, and to generalise and transfer knowledge to other possible or future scenarios via the abstraction of basic principles through reflection. According to this structure, the most important element of quality learning is how well students understand as opposed to how much they can remember.

The literature reviewed in this study also illustrates the different ways quality in learning is conceptualised relative to processes and outcomes. However, Harvey and Green (1993) suggest that if we want to find a core of criteria for assessing quality in higher education, it is essential that we understand the different conceptions of quality that inform the preferences of different stakeholders. It therefore becomes important, we argue, 
to understand students' conceptions of quality in learning. Students are the target of higher education. Knowledge about how they conceive of quality in learning might provide a starting point from which to further develop quality in the learning that takes place within higher education. This understanding has particular importance in relation to higher education in Rwanda, which is still being developed after the genocide in 1994. The aim of this article is thus to understand the different ways that students conceptualise quality in learning by drawing on a phenomenographic approach.

\section{Higher education in Rwanda}

After the 1994 genocide, the Rwandan government's public service priorities appeared to include the immediate re-establishment of the education sector, as a means of building the human capacity of the country. Vigorous transitional reforms are underway in Rwandan higher education, and these reforms are closely linked to the global forces that greatly influence the country's development agenda, aimed mainly at carving a niche in today's knowledgebased society (Ministry of Education-MINEDUC, 2010). It is presumed that, in order for Rwanda to become the competitive and diversified economy that it aspires to be, the country must have a workforce comprised of a sufficient number of people with the necessary skills to operate in an increasingly sophisticated environment (MINEDUC, 2010).

Additionally, Rwanda is striving for acceptance and integration both regionally and internationally, and the aims of the country include promoting access to quality education and enabling citizens to successfully compete in the world of work. Dynamism, mobility, competitiveness and innovativeness are some of the qualities associated with quality in learning and expected of human capital (MINEDUC, 2010). In these respects, quality in learning and employability are central policy areas in Rwanda.

In preparation for the challenges that lie ahead, Rwanda has borrowed some policies from other parts of the world. For example, the country introduced the Bologna modular system in teaching and learning practices within all higher education 
institutions. The shift to the Bologna modular system was intended to improve the quality of learning by emphasising a learnercentred approach, rather than the teacher-centred approach that previously monopolised the education system. Because of this change in the education system, teachers have been required to take into account the needs of all categories of students, as pedagogical expectations are manifested through interaction between teachers and students (Mugisha, 2010).

Transforming the quality of higher education to be fit for purpose is another priority in higher education institutions today. Quality is defined as 'fit for purpose' when education achieves its intended learning outcomes, and these outcomes are normally designed to meet the needs of Rwanda (HEC-RNQF, 2007, p. 2). In this context, engagement with employers and other stakeholders is a new strategy that higher education institutions can use to enhance the relevance of their curriculum and the employability of their graduates (MINEDUC, 2010). According to the Ministry of Education, recent studies have shown concern about academic preparedness in that many graduates lack the competence and lifelong learning skills needed for them to be successful in the workforce. The higher education that has been provided is seen as having weak linkages to the labour market, resulting in low employability of graduates and incompatibility of acquired skills with employers' needs (Kwizera, 2010; 2011; MINEDUC, 2010).

\section{Phenomenographic research on learning}

In a phenomenographic tradition, attention is directed towards questions about learning from a second order perspective, in which the experience of a phenomenon as described by others forms the basis of a researcher's description of the different ways that people conceive a given phenomenon (Marton, 1981; Trigwell, 2006). Within this tradition, numerous studies have been conducted with a focus on students' conceptions of learning (cf. Säljö, 1982; Marton, Dall'Alba \& Beaty, 1993) and the relationships among conceptions of learning, study strategies and learning outcomes (cf. Van Rossum \& Schenk, 1984; Biggs, 1989; Marton \& Säljö, 1976). A common feature of these studies is the presentation 
of variations by naming different conceptions of learning. Examples of these variations include the following: increasing one's knowledge (Pillay \& Boulton-Lewis, 2000), memorising and reproducing (Franz et al., 1996), applying (Marton et al., 1993; Pillay \& Boulton-Lewis, 2000), understanding (Marton et al., 1993; Pillay \& Boulton-Lewis, 2000), seeing something in a different way (Marton et al., 1993; Franz et al., 1996), changing as a person (Pillay \& Boulton-Lewis, 2000; Dahlgren et al., 2006), developing professional competence, obtaining grades to earn degrees (Pillay \& Boulton-Lewis, 2000), and learning as an object of study goal fulfilment (Franz et al., 1996). This study will contribute to existing research by focusing on students' conceptions of quality in learning, rather than on conceptions of learning.

\section{Methodology}

The present study takes the perspective of the participants and presupposes that there are variations in how quality in learning is conceived by students. We have employed a phenomenographic approach, resting on a basic assumption that individuals vary with regard to how they experience, conceptualise, understand, perceive, and apprehend various phenomena in the surrounding world. The words 'experience', 'conceive', 'conceptualise' and 'understand' are used interchangeably. Our point is to suggest that the limited number of ways in which a certain phenomenon appears to people can be found, regardless of whether they are embedded in immediate experience of the phenomenon or in reflected thought about the same phenomenon.

The essence of this approach is a relational qualitative perspective that aims to describe key aspects of variation in the collective experience of phenomena, rather than focusing on individual experiences (cf. Trigwell, 2006). Thus, it yields a limited number of internally related categories describing the variations, usually defined as an outcome space. This study adopted a second order perspective, in which analysis was based on the conceptions of quality in learning that were expressed by students in the interviews. The focus has been on key aspects of the collective experience of variation, rather than the richness of individual 
experience, leading to a limited number of qualitatively distinct categories of description.

\section{The empirical study}

\section{Participants}

The empirical material consisted of interviews with university students in either of the last two years of their programs, equally distributed over the four programs of medicine, agriculture, accounting, and education. This selection is grounded in the phenomenographic idea of heterogeneity at the heart of the data collection and is an attempt to maximise the variation of perspectives. Thus, the rich data involved experiences from professional, natural science, and social science courses. In phenomenographic research, given sampling requirements for purposeful variation, a participant group size of between 15 and 20 is considered to be sufficiently large to reveal most of the possible variations and to allow for a defensible interpretation (Trigwell, 2000). Based on this understanding, a group of 20 university students from different study programs were interviewed in order to maximise variation. The students were selected on a 'first come first serve' basis; the first 5 students registered from each program were considered for interviews. In the results section, we refer to the informants with codes to increase transparency in how the quotations have been distributed and to maintain the anonymity of the interviewees.

\section{Data collection and analysis}

The data collection was carried out via semi-structured interviews with the scope of an open structure. In our investigation, interview questions were pilot tested and then revised before in-depth semistructured interviews were conducted. The domains of inquiry were general university experience, study experience, and preparedness for work. The initial questions for each domain of inquiry were posed in identical wordings to all informants. The interview guide comprised only the entry questions, and the interviews developed to a large extent based on the input of the 
respondents. Each interview lasted between 60 and 90 minutes. All communication was tape-recorded, transcribed, and subjected to qualitative analysis. Ethical concerns relating to the participants' informed consent, confidentiality, withdrawals and use of materials (APA, 2010; Barett, 2007) were addressed throughout the study.

A phenomenographic approach was employed in analysing the data pertaining to students' conceptions of quality in learning. One specific interest was how students responded to the following question, which was part of the domain of inquiry concerning study experience: What do you understand by quality in learning? The transcripts were qualitatively analysed and categorised, with a focus on similarities and differences in ways of experiencing and understanding the phenomenon of quality in learning. The authors were involved in developing the analysis, and a process of negotiated consensus was used to reach the final meaning and labelling of the categories in the outcome space. The primary analysis of interview data was conducted according to phenomenographic procedures, following several analytical phases recommended by Dahlgren and Fallsberg (1991).

This analysis involved familiarisation as the initial phase. To develop an overview of students' understanding of quality in learning, the researchers conducted detailed readings of the transcripts. This process helped to identify from the transcribed data the statements that appeared to be significant and representative of the phenomenon of quality in learning. A condensed version of preliminary statements was then constructed. This version was developed through various compilations and reductions, which emphasised completeness and representativity. Characteristic aspects of each statement that connected to the aim of the study were identified, and these aspects were later used to unveil commonalities and differences within the answers. This step has been named the comparison phase. Based on the similarities and the differences identified in the comparison phase, the analysis continued with the phase of grouping the answers that appeared to have similar characteristics. This grouping was performed repeatedly to ensure that there were no overlapping groups and resulted in four empirically based categories. The next 
phase was articulation, in which each category was described, showing its unique qualifications regarding the phenomenon and the internal relationships within category answers. Based on the description given to each category, labelling was accomplished by constructing a suitable linguistic expression. Finally, in the contrast phase, internal relations among categories were generated. An outcome space of four qualitatively different (but related) ways of conceptualising quality in learning was generated (but not hierarchically structured).

\section{Results}

In the account of the results, a description of the outcome space is given. From the interviews with 20 students, four qualitatively different (but related) ways of conceptualising quality in learning were generated. The description below shows what makes the categories of conceptions different (or variations). The focus is on aspects that show differences in ways of conceptualising the phenomenon of quality in learning. Later, we articulate the internal relations between the different categories of conceptions (or similarities). The categories are defined with a name and then presented with excerpts from the interviews. The excerpts are followed by a code with letters representing programs as follows: $\mathrm{M}$ for medicine, G for agriculture, AC for accounting, and $\mathrm{E}$ for education. Briefly, the different ways that students conceptualise quality in learning include the following:

A-Transformation: conceptualising quality in learning as personal development;

B-Practice: conceptualising quality in learning as the ability to function by transferring an acquired knowledge or skill to the world of work;

C-Knowledge durability: conceptualising quality in learning as the lasting usefulness of knowledge; and 
D-Employability: conceptualising quality in learning as the ability to gain a job and perform well and to work in various places.

\section{Quality in learning as transformation}

Students conceive of quality in learning as transformation, and their interpretation of quality is focused on experiencing change or value addition. Aspects of this interpretation that are discerned from the data include becoming an intellectual, feeling better than before, and possessing knowledge. Self-development and value addition become the focus of each of these aspects. One student expressed these ideas as follows:

Quality in learning means getting something varied, you are supposed to leave better than when you came to the university, as an intellectual, as a learned person, and as a student. When you go out into the world you should make a difference (M011).

Others conceive of quality as a condition of gaining a new experience. They associate gaining experience of something new with possessing knowledge. For example, a student explains as follows:

Quality in learning is gaining experience of something and feeling that you know, e.g., I have gained communicative skills through experiencing writing and reading tasks in my study work (E062).

Other students conceive of quality in learning in terms of improvement and being recognised as different. This concept is illustrated by the following quotation:

Quality in learning is experiencing improvement with the knowledge and skills you get from your institution. That is different from the person who did not study or join the university (G028).

The above illustrations constitute aspects of knowledge change (which could be associated with an aim of understanding) and are oriented towards personal concerns and the context of education. 
The connection to a work context is not explicitly mentioned in these examples. In other words, quality in learning is conceived as personal improvement, especially while attending a university. A connection with work could most likely be implied but is not a priority.

\section{Quality in learning as practice}

Students also conceive of quality in learning as the ability to function successfully in the world of work. Aspects of this interpretation in the data is knowledge and skills that can be used in the world of work, the ability to transfer theoretical knowledge into practical solutions during work life, and the ability to practice one's profession. Students thus conceive of quality in learning as the ability to practice or implement in the world of work the knowledge and skills gained while attending a university, and therefore this conception of quality in learning has been labelled practice. Below are some excerpts from students' answers. First we have some students who point to quality in learning in terms of being able to apply knowledge to practice:

To me, quality learning would be like the kinds of things we study that are applicable when we get jobs (M012).

When you are able to turn the material you are given in class into practice. The ability to transfer the knowledge from school to the field (M024).

Making a learner able and capable of performing his/her job (AC041).

There are also students who conceive quality in learning as that which helps you to define and solve problems.

Quality is having the necessary skills to present and solve problems in your profession (G007).

From the above responses, we generate a connection between education and work. Hence, this conception of quality in learning is work-oriented. 


\section{Quality in learning as knowledge durability}

Durability of knowledge is conceptualised as quality in cases in which the lasting usefulness of knowledge is the focal point. Time constitutes the focal meaning of this conception. Students associate quality in learning with knowledge remaining relevant long after school. Durability becomes the relational element between responses referring to 'lasting usefulness of knowledge' and responses such as 'useful life of knowledge extends beyond grades'. Thus, these answers have been labelled as knowledge durability. Below are some excerpts from students' answers:

....this would be learning or being taught something, then twothree years down the road you can still apply it; not just cramming for exams only (M010).

Quality learning I would say is the learning that allows students to acquire knowledge that does not stop at school or in our books but one can easily practice it long after school (E067).

According to these responses, emphasis is placed on durability, which may be quantitative in terms of time. This interpretation of quality focuses on the length of time that knowledge acquired from school will be considered relevant in relation to the demands of work. Implicit is the concept that knowledge has to be relevant to the needs of work if it is to achieve durability. Thus, a connection between education and work can be discerned in this category.

\section{Quality in learning as employability}

This category was organised based on characteristics such as the ability to compete and win on the labour market, the ability to obtain a job, the ability to perform well, and the ability to work anywhere. Students conceptualise quality in learning as developing the knowledge and skills necessary to obtain a job and to better position themselves on the labour market. The characteristics of competitiveness, securing a job, performance, and mobility (or the ability to work anywhere) all constitute the 
conception of quality in learning as employability. Below are some examples of answers:

Quality is having the necessary skills to enable you to compete with others and win a job and be capable of working anywhere (G007).

Quality in learning would be equipping the learner with enough skills and knowledge to be able to competitively perform in his professional career (AC030).

I understand quality in learning as supporting students to be professional and after graduation to be competitive in the labour market. Our country has joined the East African Community so I think it would be a good thing if the learning at our institutions supported the students so that by the time they graduate, they can be capable of competing with our fellow partners from the region (M013).

According to the illustrations above, students conceive of the workforce as a world of competition in which better individuals can survive. Quality in learning is associated with having different experiences, being better positioned in a competitive marketplace, and having the skills and capacities to surpass others. Additionally, the characteristics of person-oriented concerns, the ability to change context and knowledge exchange can be discerned in this category.

\section{Relations between categories}

An outcome space is conceptualised to a higher level of contrast when relations are generated among the categories of transformation-A, practice-B, durability-C, and employability-D. The categories are joined together and related by the themes of knowledge and transferability.

Knowledge becomes the relational bond among categories A, B, $C$, and D. Common to these categories is an emphasis on knowledge as a primary need. This knowledge is irrespective of the different aspects or meanings associated with it that generate variations between the categories pertaining to quality in learning. 
Conceptual meanings generated from these categories are that knowledge influences personal transformation in terms of value addition, knowledge supports individuals to handle work needs in practical ways, knowledge matches work needs in order to have lasting usefulness, and knowledge supports graduates to secure jobs and maintain their employability.

It is also possible to see a relationship among categories B, C, and $\mathrm{D}$ regarding transferability of knowledge. Common to these categories is the idea that students can move from education to work and be successful in their endeavours. The conceptions of ability to practice, knowledge durability and employability reflect the idea of being flexible in terms of changes in context and over the course of time. According to students' conceptions, quality learning supports them to successfully practice their knowledge and skills in varied and changing situations and maintains their employability through changes in context and over the course of time. Understanding is another important factor that might be associated with categories B, C, and D. Understanding could allow students to transfer theories into practice, understanding might support students to benefit from their knowledge and skills long after school, and understanding knowledge and skills could support students to perform and to maintain the jobs that they secure.

On the other hand, the category of transformation-A lacks the emphasis on transferability and instead is focused on knowledge development, value addition and change in a formal educational context. Connection to work is not explicitly mentioned even though it could have been implied. However, the category does indeed include ideas about understanding as will be elaborated on in the next section.

\section{Discussion}

This study has focused on students' conceptions of quality in learning. This helped to avoid considering conceptions of learning as related only to the educational context and allowed for 
discussion of the relationship between education and work. While phenomenographic studies have concentrated primarily on conceptions of learning, the findings in this study show that, by adding the aspect of quality, a wider perspective on students' understanding of learning emerges. An outcome space of four qualitatively different (but related) ways of understanding quality in learning was generated. Students conceptualise quality in learning as transformation, as practice, as knowledge durability, and as employability.

This discussion will begin with conceptions $A$ and $B$, which share an understanding with conceptions mentioned in previous studies (e.g., Marton et al., 1993; Dahlgren et al., 2006; Franz et al., 1996). Subsequently, categories C and D will be related to contemporary discussions about employability.

Students conceptualise quality in learning as transformation. This conception is formed by the aspects of becoming an intellectual, improving oneself, and possessing knowledge. Personal development in terms of value addition becomes an important aspect of learning and indicator of quality. A typical feature of answers in this category is that formal schooling is an essential part of life. This feature parallels Harvey and Green's (1993) suggestion that quality education is about enhancing a student's capabilities so that his/her understandings, attitudes and objectives evolve in the course of the study process (thereby creating value addition) and about empowering students by giving them power to influence their own transformation. In other words, transformation is about doing something to develop a student's capabilities to continuously develop themselves and the society (Harvey \& Knight, 1996).

Further, the conception of transformation brings out the idea of improvement from one point to another, which might eventually lead us to the idea of levels of understanding (cf. Biggs \& Collis, 1982). In this line of reasoning, Marton et al. (1993) argue that the conception of changing as a person is concerned with the constitution of meaning and is closely related to understanding. This conception reflects a view of learning as an active process of seeking meaning, leading to some type of transformation in one's 
view of things or in oneself; it can also be seen as having a formal educational orientation (Dahlgren et al., 2006).

Students also conceptualise quality in learning as practice. This conception associates quality in learning with application of acquired knowledge and skills. Students conceive of quality in learning as a characteristic that enables learners to develop the ability to practice their knowledge and skills and to offer practical solutions at work. The ability to function could be established as the focus of this conception. Related to this idea is the abstract level of understanding of the SOLO taxonomy, especially when students develop the capacity to generalise and to transfer meaning to future scenarios via the abstraction of basic principles (Biggs \& Collis, 1982).

Further, the students' wish to function parallels the idea of students developing a critical ability (Harvey \& Green, 1993) as well as a commitment (Kemenade, Pupius \& Hardjono, 2008; Nyström, 2008). According to Harvey and Green (1993), developing a critical ability is an educational transformative quality that attempts to empower students not just as customers in the education process but for life. They explain that 'developing critical ability goes beyond requiring students to learn a body of knowledge and be able to apply it analytically. In this sense of empowerment, quality is seen in terms of the extent to which the education system transforms the conceptual ability and selfawareness of the students'. According to this interpretation, education empowers students so that they are prepared for life and are transformed into citizens of the world, anticipating that they will become full participants in the community of practice.

Additionally, it is possible to see a relationship between the conception of practice (or the ability to function) and what previously has been defined as fit for purpose (meaning the association of quality learning with the provision of an appropriate balance of knowledge, skills and understanding to achieve intended learning outcomes) (Harvey \& green, 1993; HEC-RNQF, 2007). On the other hand, Marton et al. (1993) interpreted the conception of practice (which they named applying) as essentially related to acquisition of knowledge, facts or methods for later use, and thus their conception does not focus on meaning related to 
understanding. They illustrate the conception of applying as a reflection of a quantitative belief that does not go beyond reproducing and applying what has been learnt.

\section{Knowledge durability and employability}

The dimensions of knowledge durability and employability are significant variations in conceptions of quality in learning that are foregrounded in this study. Adding the aspect of quality to conceptions of learning allows one to think beyond the context of formal schooling in which students conceptualise learning as knowledge accumulation, reproduction, understanding, personal development, and goal fulfilment. Rather, students extend their conceptualisation of learning by emphasising connection to work life. For example, according to the study participants, quality in learning is evidenced by durability of knowledge and employability of students.

The conception of knowledge durability connects quality with lasting usefulness of knowledge. A crucial aspect of this conception is the length of time that knowledge acquired while at university will be considered useful in the world of work. This factor raises the issue of relevance of knowledge, taking into account changes in context and over the course of time. In this respect, transferability of knowledge and skills over space and time is worth considering in regard to knowledge durability. However, how knowledge becomes durable is not mentioned. It is possible that knowledge needs to be stable to remain durable. Alternatively, knowledge needs to be modernised to be transferable and adaptable over time and space and to thereby achieve lasting usefulness or durability.

If knowledge needs to be modernised, responsibility is placed on the individual to continually assess the situation, to specify what is needed and to update her/his knowledge by filling gaps. This concept endorses the discourse of lifelong learning, the concept of individual responsibility, and the need for adaptability and flexibility in the world of work (cf. Fejes, 2010; Garsten \& Jacobsson, 2004; Rose, 1999). It would be interesting to know if students are empowered to monitor, control and make decisions 
about the process of improving their knowledge and skills as they transition from education to work. In this regard, Knight and Yorke (2003) emphasise the need for learning to support students in the process of discovering what they can afford, what might be learnt, and how and why they could improve their knowledge and skills.

The conception of employability connects quality in learning to developing the knowledge and skills necessary to support one to gain a job and to better position individuals on the labour market. This conception is driven by the aspects of competitiveness, better positioning on the labour market, securing a job, performance, the ability to change context, knowledge exchange and mobility. Students view learning as an essential part of their future work life, especially in terms of becoming employable.

A relationship that can be discerned from these aspects is that one has to experience quality learning in terms of selfdevelopment (as in awareness and transferability of knowledge and skills) if one is to become competitive and employable. This reasoning is in line with Knight and Yorke's (2003) idea that employability and good learning are highly compatible. According to their arguments, programs and learning environments must be designed that combine a concern for learning with the development of student employability. They suggest that student employability could be fostered by a learning culture that helps students know what they are learning and why and that helps them know how to develop the claims to achievement that make them more employable. It is important to understand that an increased concern for employability may result in higher expectations being placed upon students, as often students are positioned as being responsible for transforming themselves into employable citizens. Fejes (2010) makes it clear that learning today extends beyond formal schooling to include all of life. As life becomes constructed as a life of learning, learning extends from learning per se to include new ideas about how governing should operate in the present. People need to take responsibility to become constant learners, and declining such an invitation to take responsibility positions citizens as non-desirable and nonemployable. 


\section{Conclusion}

In times of great changes in higher education in Rwanda where quality of learning is a central policy area, dynamism, competitiveness and innovativeness are expected of human capital (MINEDUC, 2010). In the present study, students conceived of quality in learning as transformation, as practice, as knowledge durability, and as employability. The main contribution of this study was exploring the relationship between education and work. In our analysis, the ability to practice (or function), knowledge durability, and employability were emphasised and associated with quality in the context of university learning. In brief, students conceptualise quality in learning in terms of transferring knowledge and skills to the world of work and being successful in their endeavours.

While the higher education institutions in Rwanda adopt the Bologna system to promote quality learning, the findings indicate that learning culture, program design, and learning environment could also be vital considerations (Knight \& Yorke, 2003). One way to foster quality in learning and student employability would be to ensure that the learning process helps students to know what they are learning and why and to know how to develop the claims to achievement that make them more employable. The findings show that, if students are to achieve the competitiveness and mobility that have been emphasised by Rwandan higher education (MINEDUC, 2010), then the following characteristics will become essential parts of university learning: promoting flexibility and adaptability and empowering students to become managers so that they can control, monitor and make decisions as to what they can afford, what might be learnt to fill gaps in knowledge, and how to achieve these steps (so that they can maintain their employability). In other words, more is expected of students in terms of learning and responsibility if students are to make strong, well-evidenced claims of employability. Individuals are expected to become lifelong learners in order to continually upgrade or update their knowledge not only to enhance the lasting usefulness of their knowledge but also to support their continued employability over time and through changes in context. 
The study concludes by highlighting an important contribution to the phenomenographic research on learning in higher education, especially from the perspective of learners. Adding the aspect of quality to the analysis of learning allows students to go beyond conceptualising learning as increasing one's knowledge, reproduction, understanding, self-development, and goal fulfilment and to conceive of learning also in terms of knowledge durability (or lasting usefulness of knowledge) and employability. Thus, this study contributes the categories of knowledge durability and employability as vital aspects when we discuss quality in learning from the perspective of students.

The findings and their close relationship to contemporary discourses on employability (cf. Fejes, 2010; Garsten \& Jacobsson, 2004)) raise some important questions for further interrogation, including the following: How do conceptions of quality in learning differ among different stakeholders? Are some conceptions of quality in learning more desirable than others? Why? For those involved in higher education, the findings provide a starting point to elaborate on the questions of what we mean by quality in learning and how we can improve this quality.

\section{Acknowledgements}

We wish to acknowledge our fruitful collaboration over the years with Professor Lars Owe Dahlgren, who most sadly passed away during the finalisation of this article. You will be greatly missed.

\section{References}

APA. (2010). Ethical Principles of Psychologists and Code of Conduct. $\begin{array}{lllll}\text { (retrieved } & 16 & \text { August } & \text { 2011) }\end{array}$ http://www.apa.org/ethics/code/index.aspx

Barett, M. (2007). Practical and ethical issues in planning research. In G. Breakell, S. Hammond, C. Fife-Schaw, and A. Smith (Eds.), Research methods in psychology (pp. 24-48). London: Sage Publications.

Biggs. J. (1989). Approaches to enhancement of tertiary teaching. Higher Education Research and Development 8, 7-25. 
Biggs, J.B., \& Collis, K. F. (1982). Evaluating the quality of learning: the SOLO taxonomy (structure, of the observed learning outcome). New York: Academic Press.

Dahlgren, L. O., \& Fallsberg, M. (1991). Phenonomenography as a qualitative approach in social pharmacy research. Journal of Social and Administrative Pharmacy, 8(4), 150-156.

Dahlgren L. O., Abrandt-Dahlgren, M. Hult, H., Hård af Segerstad, H, Szkudlarek, T., Gajda, M., Jurgiel, A., Kopciewicz, L., Merzec, J. Meczkowska, A. \& Mendel, M. (2006). Conceptions of learning among teachers and students in higher education: a Swedish-Polish comparative study, In Anthology of Social and Behavioral Sciences, ed. T. Maliszewiski, W. J. Wojtowicz, and J. Zerko, 89-115. Linköpings: Linköpings Universitet

Fejes, A. (2010). Discourses on employability: Constituting the responsible citizen. Studies in Continuing Education, 32(2), 89-102.

Franz, J., Ferreir, L., Loh, H., Pendergast, D., Service, M., Stormont, D., Taylor, L., Thambiratnam, D. \& Williamsson, B. B. (1996). Students' and Learners' Conceptions of Learning in context: An interdisciplinary Study. Teaching in Higher Education, 1(3), 325-340.

Garsten, C and K. Jacobsson. 2004. Learning to be employable: an introduction. In C. Garsten and K. Jacobsson (eds), Learning to be employable: New agendas on work, responsibility and learning in a globalized world, (pp. 1-22). New York: Palgrave Macmillan.

Harvey, L. \& Green, D. (1993). Defining quality. Assessment and Evaluation in Higher education, 18(1), 9-34.

Kemenade, E., Pupius, M. \& Hardjono, T. (2008). More value to defining quality. Quality in Higher education, 14(2),175-185.

Knight, P.T. \& Yorke, M. (2003). Employability and Good Learning in Higher Education, Teaching in Higher Education, 8(1), 3-16.

Kwibuka, E. (2007). Accommodation problem hits NUR student. The New Times, Kigali. January 16. http://allafrica.com/stories/200701171255.html

Kwizera, C. (2010). Rwanda varsities to adopt modular system of teaching. The New Times, Kigali, June 29.

Kwizera, C. (2011). Rwanda varsities to adopt modular system of teaching. The New Times, Kigali, June 29.

Marton, F. (1981). Phenomenography - describing conceptions of the world around us. Instructional Science, 10, 177-200.

Marton, F., Dall'Alba, G. \& Beaty, E. (1993). Conceptions of learning. International Journal of Educational Research, 19(3), 277-300. 
Marton, F., \& Saljo, R. (1976). On qualitative differences in learning: I. Outcome and process. British Journal of Educational Psychology, 46, 4-11.

Mugisha, S. I. (2010). Assessment and study strategies: A study among Rwandan students in higher education. (Diss.) Linköping University: ISBN 978-91-7393-340-7Nyström, S. (2008). A winding roadprofessional trajectories from higher education to working life: a case study of political science and psychology graduates. Studies in Continuing Education, 30(2), 215-229.

Ministry of education. (2010). Rwanda Education Sector Strategic Plan 2010-2015. Retrieved April 4, 2011, http://library.educationcommons.rw

National Council for Higher Education. (2007). Rwanda National Qualification Framework. Retrieved April 4, 2011, from http://www.hec.gov.rw/IMG/pdf/Rwanda_National_Qualifications_Fram ework_for_Higher_Education_Institutions.pdf

Pillay H., \& Boulton-Lewis, G. (2000). Variations in Conceptions of Learning in Construction Technology: Implications of Learning. The Journal of Education and Work, 13(2), 163-81.

Rose, N. (1999). Powers of Freedom: Reframing Political Thought. Cambridge: Cambridge University Press.

Stråth, B. (2000). After full employment and the breakdown of conventions of social responsibility. In B. Stråth (Ed.), After full employment: European discourse on work and flexibility, (pp. 11-31). Brussels: Peter Lang

Säljö, R. (1982). Learning and Understanding: A study of differences in constructing meaning from a text. Göteborg: Acta Universitatis Gothoburgensis.

Trigwell, K. (2000). A phenomenographic interview on phenomenography. In J. Bowden \& E. Walsh (eds.), Phenomenography, (pp. 47-61). Melbourne: RMIT University Press.

Trigwell, K. (2006). Phenomenography: An approach to research into geography education. Journal of Geography in Higher Education, 30(2),,367-372.

Van Rossum, E.J. \& Schenk, S.M. (1984). The relationship between learning conception, study strategies and learning outcome. British Journal of Educational Psychology, 54(1), 73-83.

Williams, C. (2005). The discursive construction of the competent learner-worker: From key competencies to employability skills. Studies in Continuing Education, 27(1), 33-49. 